\title{
PÚBLICO E PRIVADO NA FORMAÇÃO SOCIAL BRASILEIRA: VELHAS, NOVAS E NOVÍSSIMAS TENSÕES
}

THE NOTIONS OF PUBLIC AND PRIVATE IN THE SOCIAL DEVELOPMENT OF BRAZIL: OLD, NEW AND VERY NEW CONFLICTS

Marco Aurélio Nogueira ${ }^{1}$

Resumo $\mathrm{O}$ artigo procura traçar um quadro panorâmico de alguns momentos da história brasileira para tentar encontrar as determinações que fizeram com que a intersubjetividade e a 'eticidade' mergulhassem num padrão deletério e nele ficassem amarradas. Busca assim explicar a dificuldade quase crônica que a elite política brasileira tem de governar de modo republicano, ou seja, fazendo com que o interesse público prevaleça democraticamente sobre os interesses privados, sejam esses interesses os do dinheiro, do voto ou das corporações. Sem virtude pública constituída e sedimentada na sociedade e na cultura política, o Brasil cresceu com dificuldades para se aprumar em termos democráticos e republicanos. Mas é uma comunidade que se reconhece como tal, que compartilha uma cultura rica e expressiva, que bem ou mal tem um sistema político e de governo.

Palavras-chave republicanismo; cultura política; comunidade política; privatismo; ética pública.
Abstract The present article intends to produce a general overview of a few moments of the Brazilian history in order to point out what influences our intersubjectivity and ethic codes to have formed and maintained an unhealthy pattern. It seeks, therefore, to explain why the Brazilian political elite is almost chronically unskilled in the republican government model, that is, a model in which the public interest democratically overcomes all private interests - either financial, electoral or corporative. Since the public virtue of Brazil is not yet fully constituted neither matured, the country has had major difficulties to promote its democratic and republican development. However, Brazil is a community that recognizes the flaw, that shares a rich and expressive culture and, for good or bad, has $a$ political and government system.

Keywords republicanism; political culture; political community; privatism; public ethics. 


\section{Introdução}

A situação de crise política e governamental em que o Brasil ingressou a partir de junho de 2005 está repondo, em bases seguramente diferentes, certos temas e problemas que integraram com destaque a formação do Estado e do regime republicano entre nós. Não foram poucos os estudiosos que se dedicaram a analisar a natureza desses problemas e seu impacto na constituição do Brasil moderno. O foco dessas análises muitas vezes repousou, de forma não-excludente, nas complexas relações que se estabeleceram no correr de nossa história entre o mundo público e o mundo privado, com seus desdobramentos e efeitos sobre a formatação da sociedade, o padrão dos relacionamentos sociais, a cultura política e a configuração institucional.

Quando, nos primeiros anos do século XXI e no âmbito de um governo repleto de promessas populares e reformadoras, deparamo-nos com uma nova onda de 'privatizações' do público e de aparelhamento do Estado para fins particulares (no caso, partidários), é como se todo o passado que se imaginava superado voltasse a mostrar sua face e a atropelar a modernização dos hábitos públicos, da cultura política e das instituições estatais do país e, pior, a comprometer mais uma vez o esforço para reduzir as disparidades sociais que dilaceram a população.

Tornou-se inevitável, assim, que nos puséssemos novamente a interrogar o passado, como se nele pudéssemos encontrar a chave para explicar a dificuldade quase crônica que a elite política brasileira tem de governar de modo republicano, ou seja, fazendo com que o interesse público prevaleça democraticamente sobre os interesses privados, sejam esses interesses os do dinheiro, do voto ou das corporações. Sem virtude republicana constituída e sedimentada na sociedade e na cultura política, o Brasil cresceu com dificuldades para se aprumar em termos públicos e republicanos.

A mancha da corrupção - a do roubo e da sonegação, mas também a do desvirtuamento da relação entre mundo público e mundo privado - tem se mostrado, assim, forte o suficiente para se reproduzir ad nauseam e invadir todos os cantos do espectro político e associativo, da direita à esquerda, dos partidos aos sindicatos, das empresas às escolas.

É importante atentarmos para a dimensão do fato. Não há corrupção apenas quando um agente público apropria-se indevidamente de fundos que existem para uso público ou faz valer a força de seu cargo para obter recursos para campanhas eleitorais ou para seu próprio enriquecimento, ou, ainda, quando um partido organiza um aparato arrecadador particular mediante a montagem de uma rede de empresas e órgãos públicos controlados e monitorados de modo privado. A corrupção é isso, em essência, mas também é mais que isso. Ela aparece na troca de favores e de privilégios entre os particulares, no uso generalizado de cargos ou de vantagens trabalhistas (lembremo-nos da 
estabilidade no serviço público) para justificar eventuais desrespeitos a expectativas socialmente estabelecidas, como seria o caso, por exemplo, de um professor que não dá aulas ou não se prepara adequadamente para dá-las, de um engenheiro ou de um médico que, como servidores públicos, executam parcialmente sua tarefa porque dividem seu tempo de trabalho com o consultório particular ou com o escritório de consultoria. Há corrupção quando inocentemente levamos canetas do escritório para casa, quando empresários sonegam impostos alegando protestar contra o "custo Brasil" ou quando o contribuinte manipula sua declaração de imposto de renda.

De certo modo, e pensando em termos abstratos, a corrupção integra a experiência humana como um todo, expressando a tensão que sempre existe entre interesses e desejos, de um lado, e normas e controles de outro. Mecanismos de cerceamento ou de constrição são sempre um convite à 'desobediência', à ultrapassagem de limites, à burla. Não funcionam melhor quando são impostos unilateralmente sobre pessoas reprimidas, amedrontadas ou bloqueadas em suas pulsões e em sua movimentação, mas sim quando são acompanhados de uma maior compreensão racional de seu valor e de sua necessidade. Não dá para se ser "contra a corrupção" sem a consideração desse fato. Uma ditadura implacável, por exemplo, na qual as regras praticamente oprimem os indivíduos, dando folga somente a alguns 'escolhidos', não é o sistema mais protegido da corrupção ou mais eficaz contra ela, muito ao contrário.

A idéia de 'virtude republicana' serve-nos precisamente para destacar um requisito essencial da comunidade que se organiza e se governa com instituições e hábitos públicos fortes, isto é, compreendidos e aceitos pelos cidadãos, tendo em sua base uma redução expressiva dos privilégios pessoais e das condições de possibilidade de imposição de um grupo ou classe sobre outros. Quando esses fatores faltam, aumentam significativamente as chances de corrupção.

Sendo um fato assim tão impregnado em nossas práticas e em nossos hábitos, a corrupção não pode ser vista apenas como um problema dos governos, dos funcionários públicos ou dos políticos. É um problema maior, que tem a ver com o padrão daquilo que poderíamos chamar não de nossa 'moralidade' - qualidade referente ao homem moral, que responde por seus atos tendo em vista sua própria consciência individual -, mas sim de nossa 'eticidade', referida ao homem ético, que responde por seus atos tendo em vista os outros homens. Não é algo que tenha a ver com o caráter singular do brasileiro, com a maior ou menor virtude intrínseca a ele, com sua natureza moral. Ele diz muito mais respeito à relação dos brasileiros com os costumes do mundo em que vivem, ao modo como se vêem enquanto membros de uma comunidade, como interagem uns com os outros e valorizam essa interação, assim como diz respeito às instituições e aos hábitos que vão emergindo dessa interação. O problema tem muito mais a ver com vida intersubjetiva e organização social que com caráter pessoal. 
Isso nos coloca a exigência de buscar suas raízes na experiência histórica nacional. Ao longo de nossa formação social produziram-se certos 'traumas' que fizeram com que nossa intersubjetividade e nossa eticidade mergulhassem num padrão deletério e nele ficassem amarradas. Nós, brasileiros, não somos um povo de corruptos e podemos perfeitamente nos colocar diante do mundo como um povo de virtudes e qualidades. Temos problemas em nossas instituições políticas, nos hábitos e nas práticas referentes ao governo e à gestão pública. Nossas elites (todas, não apenas as políticas) não são propriamente primorosas e não têm sabido acompanhar a marcha do tempo, mantendo-se atreladas a privilégios e a comportamentos 'anti-republicanos', hostis a uma vida comum mais justa e equilibrada. Apesar disso, estamos construindo uma comunidade que se reconhece como tal, que compartilha uma cultura rica e expressiva, que bem ou mal tem um sistema político e de governo. Somos filhos de uma mesma experiência coletiva, e é razoável que procuremos nela as razões que explicam nossas fragilidades.

\section{O século XIX}

Se voltarmos ao século XIX, por exemplo, podemos encontrar um interessante ponto de inflexão na campanha abolicionista, principalmente na teoria que Joaquim Nabuco estabeleceu para ela, por volta de 1883, quando publicou $O$ Abolicionismo.

Naquela época, tínhamos uma sociedade tradicional em pleno vigor, apenas levemente tocada pela modernização capitalista. A sociedade era modelada pela escravidão e dividia-se basicamente em duas partes, uma oprimindo, explorando e humilhando a outra. O Estado, agigantado artificialmente, não funcionava como um ator que se debruçasse de modo ativo sobre a sociedade, que planejasse seu desenvolvimento, a amparasse e promovesse. Não existiam, a rigor, políticas públicas. A democracia engatinhava e era tão imperfeita e tão vazia de povo que seria mesmo o caso de perguntar se existia ou cumpria alguma função.

Nabuco tinha diante dele o cenário traumático e corrosivo da escravidão. Por estar dividida em dois mundos que mal se comunicavam, por seu passado colonial, pelo modo como se formara e definira a ocupação de seu território, a sociedade parecia travada. Era dominada por famílias e por senhores de terras e de escravos. Faltavam estadistas, os atores eram precários, a história parecia se arrastar sem fim. A escravidão ocupava o centro do organismo social brasileiro, formando um verdadeiro sistema, "um ar envenenado que respiramos e absorvemos, todos e tudo". Justamente por isso, "degradava a nação toda". (Nabuco, 1988). Amesquinhava o escravo, o operário livre das cidades, as classes médias e os próprios proprietários. Bloqueava o desenvolvimento econô- 
mico e a indústria. Desvalorizava o trabalho e deformava a instrução. Desarticulando e espezinhando as classes sociais, limitava drasticamente as margens de liberdade, de democracia e de cidadania. Possibilitava o predomínio dos proprietários de escravos, que deixavam a marca de seus interesses e de suas práticas no processo político e na organização institucional. A escravidão inflava o Estado, que se tornava o "pai de nós todos", e criava um funcionalismo público repleto de vícios, dependente e parasitário. O sistema político - partidos, parlamento, governos, eleições - ficava distorcido e perdia potência.

Sem a supressão da escravidão, não seria possível uma 'constituição social' imune à imposição de preferências e de interesses particulares à comunidade política - em suma, a construção de uma ordem democrática e republicana, na qual o interesse público prevalecesse de modo incontestável, coisa que, na concepção de Nabuco, poderia acontecer mesmo sob a forma do regime monárquico. O fundamental era cortar pela raiz o império dos senhores de terras e escravos, com o que se teria uma sociedade capaz de construir um futuro comum para todos os seus integrantes.

A ordem republicana almejada pelos reformadores do século XIX, como sabemos, não veio com a instauração da República em 1889, nem com o regime por ela organizado. As oligarquias prevaleceram sobre os cidadãos, a ignorância e a miséria continuaram a fracionar a sociedade, a separar os brasileiros entre 'bons' e 'maus' e a fazer das reservas de pobres e miseráveis um fator poderoso de reprodução de elites desqualificadas - e desqualificadas porque separadas demais da sociedade e despreocupadas em relação a qualquer risco de castigo ou punição. Ao menos até a Revolução de 1930, o Brasil pouco se diferenciará da sociedade legada pela escravidão. A dimensão pública da vida era estreita, os cidadãos rareavam, as elites pareciam flutuar sobre a grande massa da população, atentas muito mais a fantasias ou a modelos ideais do que ao 'país real'.

A República trouxe consigo o compromisso de democratizar e moralizar a vida pública, ordenar um sistema jurídico-político baseado na federação e modernizar a economia através do estímulo à industrialização. No entanto, as condições do país não facilitaram nem favoreceram a reorganização republicana: diante do novo regime, ergueu-se como obstáculo a própria sociedade legada por três séculos de colonização e de escravidão e pelo autocratismo conciliador do regime monárquico constituído após a obtenção da Independência em 1822. O país ficara como que entregue a um sistema político enrijecido, burocratizado e incapaz de responder aos movimentos da economia e da sociedade. A República acabou por receber todo o impacto dessa situação: não pôde contar com qualquer sustentação popular, foi proclamada pelo exército e acabou monopolizada, após curta fase jacobina e militar, pela moderada e civilista fração cafeeira da grande burguesia agrária, capitaneada pelos republicanos paulistas. 
Deixando em segundo plano a construção da democracia e atenuando drasticamente seu reformismo, a República foi organizada a partir de um jogo político regionalista, oligárquico e excludente que reproduziu o fosso entre povo e Estado, deformou a representação e descaracterizou a própria idéia federativa, que havia sido anunciada como um de seus grandes trunfos. Apenas nominalmente seria um sistema democrático: na verdade, fincou raízes em um localismo mandonista e em práticas clientelísticas autoritárias, desinteressadas da cidadania e da liberdade política (Leal, 1975). O espírito republicano formado no embate ideológico dos finais do Império, desta forma, esfriaria gradualmente durante as três primeiras décadas da implantação do novo regime.

Quando nas décadas de 1920 e 1930 avançaram os estudos sociológicos e históricos no Brasil, o fato não passará despercebido. Sérgio Buarque de Hollanda, por exemplo, dará grande destaque à necessidade que se tinha de submeter a ordem familiar, base da vida privada, à ordem estatal - a uma espécie de "entidade imaterial e impessoal" que pairaria sobre os indivíduos e presidiria seus destinos -, único modo de se constituir uma autêntica comunidade política (Buarque de Hollanda, 1963, p. 179). Somente pela "transgressão da ordem doméstica e familiar" é que o Estado pode nascer e que "o simples indivíduo se faz cidadão, contribuinte, eleitor, elegível, recrutável e responsável, ante as leis da Cidade" (Buarque de Hollanda, 1963, p. 129). Enquanto o "homem cordial" e a cordialidade subsistissem incólumes - e com eles a mentalidade doméstica, familiar -, o Estado não teria como se completar e funcionar de modo racional, impessoal: o público seria engolido pelo privado, o coletivo pelo particular, a impessoalidade pela pessoalidade, o pacto social pela anarquia, e assim por diante. "Em terra onde todos são barões", escreverá ele, "não é possível um acordo coletivo durável, a não ser por uma força exterior respeitável e temida" (Buarque de Hollanda, 1963, p. 5).

Os pensadores mais realistas e 'autoritários', como Azevedo Amaral ou Oliveira Vianna, seguirão caminho semelhante. Pecarão pelo 'excesso' de imaginar e defender uma ordem pública reduzida ao momento da centralização e da organização estatal forte - despojando-a portanto de bases democráticas e populares -, mas serão sensíveis ao que era o grande entrave da época: a ausência de um Estado aparelhado para defender o público contra o privado, disseminar justiça social, afirmar a lei e completar a construção da nação (ver, por exemplo, Viana, 1987).

\section{República, Anos 30}

Representando um privilegiado momento do processo de construção do Estado, da reorganização urbano-industrial e da luta democrática no Brasil, a década de 1930 conteve em si a tentativa de atualizar a modernidade prometida pela República de 1889 e parcialmente comprometida pelo 
sistema de dominação que se estruturou sob os auspícios da Constituição de 1891.

Nas quatro décadas que separam o fim da Monarquia e a Revolução de 1930, o Brasil conhecerá um tumultuado e irregular processo de expansão capitalista. Desponta lenta mas firmemente uma nova civilização, urbanoindustrial, com suas classes estranhas à estrutura 'estamental' legada pelo Império, com um novo arsenal ideológico e com novas expectativas políticas. Tudo passa a ser posto em xeque, o social se torna mais transparente e mais dinâmico e faz sentir sua voz. Os grandes problemas nacionais, entre os quais destacava-se, por exemplo, o da escolarização - essencial para que se pudesse pensar em um povo de cidadãos republicanos -, passariam a ser intensamente discutidos e analisados.

Até mesmo no que representaram de preservação das estruturas que se queria superar, as realizações e promessas daqueles dez curtos anos se espalhariam pelas décadas ulteriores: organizariam a vida nacional durante o vintênio iniciado com a redemocratização de 1945 e balizariam muito da institucionalidade e da conduta política do regime ditatorial instalado com o golpe militar de 1964, deixando uma complexa herança para o país. Afinal, entre tantas outras coisas, foi naquela conturbada década que se organizou a estrutura sindical brasileira, delineou-se uma política de massas fundada numa espécie de paternalismo estatal (o 'populismo') e corporificou-se todo um modo de pensar o Estado e o serviço público, coisas que tanta importância teriam nos movimentos posteriores do capitalismo e da classe operária no Brasil.

A solução engendrada em 1930 trouxe consigo uma espécie de estatização do povo e da República: o novo regime será uma República com Estado forte e povo fraco. A recuperação das promessas republicanas - governo do povo, cidadania, democracia representativa - ficaria na dependência do fortalecimento do Estado, que funcionará como uma ponte responsável por preparar as bases da sociedade para um contato mais efetivo com as formas e os hábitos da República e da modernidade.

Os anos 30 impulsionaram a constituição de uma nova forma de Estado, mais ajustada às exigências da objetivação do capitalismo entre nós. Porém, nada se fez de modo harmonioso ou equilibrado, e muito menos de modo categórico, isto é, sem retrocessos ou paralisações. O critério foi muito mais o da conciliação que o da ruptura impetuosa. Talvez por expressar uma situação de 'crise de hegemonia', a vitória não chegou a ser incontrastável em nenhuma das frentes em que se travou a batalha modernizadora. A própria centralização política jamais seria forte o suficiente para absorver as expressões regionais de poder. $O$ sistema judiciário não se unificaria plenamente. A ampliação das bases fiscais do Estado seria relativamente lenta, impossibilitando a posse de recursos significativamente mais encorpados pela União. Nas áreas do ensino, da saúde e da previdência, pouco se avançaria em ter- 
mos da constituição de sistemas planejados e unificados (o que só começaria a ocorrer, a rigor, no início dos anos 60). Mesmo a intervenção econômica do Estado não chegaria a ser efetivamente coordenada por um órgão central de planejamento. E em que pesem todos os esforços despendidos, houve pouco avanço efetivo em termos de modernização e de racionalização administrativas, e a nova burocracia vinculada ao Dasp (Departamento Administrativo do Serviço Público) conviveria durante muito tempo com o velho funcionalismo ainda preso ao cartorialismo tradicional, bem pouco impessoal e bem pouco republicano (Nogueira, 1998).

Além do mais, houve uma forte dose de 'seletividade': as massas rurais permaneceram alijadas da esfera de alcance do aparato público, direcionado exclusivamente para os setores urbanos assalariados e sindicalizados. $\mathrm{O}$ aparelho social do Estado também não chegou a propiciar - seja em termos de saúde, seja em termos de educação ou previdência - a oferta de decisões e de serviços públicos capazes de atender às demandas objetivas da população trabalhadora. Sequer os trabalhadores sindicalizados puderam dispor de um categórico atendimento às suas reivindicações e necessidades. A cidadania daqueles anos foi restrita e esteve fortemente contaminada por componentes de injustiça e de discriminação.

O modelo de Estado que então se delineia será corporativista e nele os sindicatos terão muito maior peso que os partidos políticos. A via corporativa servirá ao novo Estado tanto para atenuar o jogo político até então predominante - conseguindo deste modo enfraquecer as elites agrário-exportadoras - quanto para calçar a subordinação das classes subalternas. Acabaria por restringir as possibilidades de instauração e de aprofundamento de uma ordem democrática.

Houve muita falta de sintonia entre o tempo da economia e o tempo da política, entre o tempo do Estado-governo e o tempo da representação, fato já registrado por muitas vertentes da bibliografia especializada (ver, por exemplo, Campello de Souza, 1976). Os anos 30 configurarão uma fase de turbulência e instabilidade, sobretudo porque neles se tentará a institucionalização de um poder reformador sobre uma estrutura agrária que se mostrava resistente ao tempo e sobre uma estrutura política que não conseguia se modernizar com rapidez. Entre os múltiplos efeitos de longa duração desses desajustes, encontram-se a hiper-centralização e a natureza 'personalista' do regime presidencial, a forte tendência a um 'decisionismo' de tipo autoritário na cultura governamental, a precarização do sistema partidário, os variados problemas de afirmação e funcionamento do Legislativo e, por fim, uma nova problematização da cidadania e da dialética entre público e privado.

O Estado formatado nos anos 30 avançou pelas décadas seguintes, ultrapassando a redemocratização de 1945, o golpe de 1964 e a nova redemocratização de 1985. Mostrou força e eficácia, autoridade e empreendedorismo, praticamente liderando a marcha do capitalismo e da industrialização no país. Constituirá to- 
da uma cultura para si. O Estado da Era Vargas será o grande modelo do Brasil moderno, uma verdadeira usina da institucionalidade política e da administração pública. Expressará um pacto social de tipo 'desenvolvimentista', que passará por ajustes e adaptações ao longo do tempo (conforme os períodos democráticos e os ditatoriais).

Com ele se estabilizará um padrão de cidadania, que continuou "regulada" (Santos, 1979), distante da consideração dos temas 'individuais' e tendo na identificação com o Estado e a nação seu eixo constitutivo básico. Reproduzir-se-á também um padrão perverso de presidencialismo: plebiscitário, fundado num mix de corporativismo e carisma, dependente da iniciativa mediadora do chefe do Estado e da montagem de coalizões governantes desprovidas de caráter programático e entregues a um relacionamento fisiológico com o governo, expediente que, como sabemos bem, permanece vivo ainda nos dias atuais.

O arranjo estatal desenhado nos anos 30 politizou de modo distorcido a administração pública. Facilitou a 'balcanização' do aparato administrativo e bloqueou a colocação em prática de projetos reformadores capazes de modernizar a administração, aumentar sua eficiência e sua eficácia e dar a ela maior afastamento em relação ao mundo dos interesses particulares. Não foi inteiramente republicano, nem democrático.

\section{Ditaduras, 1964}

Houve ditadura até 1945, e a 'democracia populista' de massas que então se seguiu terminou violentamente com o golpe militar de 1964. A vida republicana se fez aos trancos e barrancos, evoluindo de forma instável e sendo regularmente atropelada por longos períodos ditatoriais, que acabaram por reforçar os traumas que abalavam a nossa eticidade.

Por proibirem a liberdade e a democracia, as ditaduras deformam a educação cívica e a proliferação de uma cultura democrática; não fomentam o espírito republicano, até mesmo porque os próprios gases tóxicos que destilam, como regimes fechados em si, acabam por sufocar as virtudes públicas e a estimular excessos de todo tipo, inclusive e sobretudo os que costumamos associar à corrupção ou à 'privatização do público'. Só pode existir República - e, portanto, cultura republicana - quando os homens interagem uns com os outros em condições de liberdade, de igualdade fundamental e de 'Paidéia', isto é, de formação do homem ético.

Ainda que tenhamos avançado em termos de liberdade, de igualdade de oportunidades e de organização de um sistema escolar universal, é evidente que temos déficits gravíssimos em todos esses planos, sobretudo quando olhamos de modo panorâmico para o país em seu conjunto. Não pudemos 
acumular historicamente os requisitos básicos para sermos consistentemente republicanos.

O golpe de 1964 não representou um pesadelo em uma noite de verão. Deitou raízes na vida nacional. Por longos vinte anos o Brasil viveu sob suas asas e seu patrocínio. O próprio reencontro com a democracia só teve início efetivo por iniciativa de um dos generais que ocuparam a Presidência da República, Ernesto Geisel, quando, ao terminar seu mandato, em 1979, e transferir o cargo para o último general, João Batista Figueiredo, legou ao país uma ditadura já enfraquecida (ainda que, em seus estertores, continuasse a ser violenta e arbitrária), deixando o caminho livre para que a lógica das coisas, a pressão social e a iniciativa dos políticos democráticos terminassem por enterrá-la.

Entre 1964 e 1984, o país explodiu em termos capitalistas. Expandiu suas forças produtivas, internacionalizou a economia, dinamizou a agricultura e se industrializou. Movimentou-se freneticamente. Tornou-se mais capitalista, mais moderno, mais autoritário e mais injusto, radicalizando uma tendência que vinha se acentuando desde a década de 1950. O conjunto das mudanças repercutiu com força na política, alterando comportamentos, fazendo proliferar novos interesses e transformando os padrões de participação. A população multiplicou-se formidavelmente: 70 milhões de pessoas em 1960 transformaram-se em 120 milhões em 1980, ao passo que, nesse mesmo período, a população urbana cresceu de $44 \%$ para $67 \%$ e a rural decresceu de $55 \%$ para $32 \%$. Como a ditadura não cancelou as eleições, o número de eleitores também se expandiu, alcançando a casa dos 58 milhões no pleito de 1982, quase a totalidade da população adulta alfabetizada, número que praticamente dobraria nas décadas seguintes.

Os sucessivos governos militares reproduziram os traços mais perversos da história nacional e criaram muitas outras mazelas. Suas escolhas fracionaram a sociedade em compartimentos estanques, presos a interesses particularistas e desejosos de um diálogo direto com o Estado, sem a mediação de partidos ou de instituições representativas. Tornaram extremamente complexa a trama política e extremamente desgastante o jogo em torno do poder. A movimentação social por eles ativada, ao se divorciar da democracia, acentuou seus traços 'selvagens' e pré-políticos. A recessão posterior ao fracasso do 'milagre econômico' fez com que o país ingressasse numa espécie de guerra de todos contra todos. E foi essa sociedade que, alguns anos depois, experimentou a transição democrática.

Em decorrência disso, o processo de democratização não conseguiu encontrar base e impulso para se desenvolver de maneira acelerada ou impetuosa. Embora ganhando força e diversificação, a sociedade civil não foi capaz de estabelecer maiores vínculos orgânicos com a sociedade política; da mesma forma, avançou a consciência democrática e ampliou-se a participação, 
mas faltaram instâncias capazes de agregar e de organizar em nível superior (político-estatal) os múltiplos interesses sociais e, especialmente, de dar vazão e operacionalidade às reivindicações populares.

O país avançou rumo ao final do século de modo seguramente não-linear. Conheceu uma Constituição 'cidadã' em 1988, voltou a eleger seus presidentes, normalizou a vida democrática, domou a inflação, tomou consciência da questão do Estado e da gestão pública, mergulhou na globalização. Mas continuou claudicando na área social, que não mudará significativamente de perfil. Houve melhorias tópicas na distribuição de renda, mas pouca tradução em termos de qualidade de vida. Se antes se podia dizer que a pobreza estava 'represada' em algumas regiões do país, passou-se a constatar que ela se transfigurou, cresceu em direções novas e assumiu formas mais perversas, rompendo limites e fronteiras espaciais e ressurgindo (ou se alastrando) em áreas onde se imaginava banida.

Em suma, entramos no século XXI com um enorme fardo nas costas, que desafiou todos os governos da década de 1990. O país flertou firme com o neoliberalismo, ajustou seu Estado, assistiu à ascensão política e eleitoral do Partido dos Trabalhadores (PT) e à consolidação da democracia. As sucessões presidenciais passaram a ser feitas limpa e civilizadamente, sem sobressaltos ou golpes de mão. Ao mesmo tempo, o país se globalizou, se fragmentou e se diferenciou, adquirindo doses adicionais de individualismo e de complexidade. Passou a conviver com uma trama de problemas e pressões difícil de ser decodificada e assimilada. Tornou-se 'pós-moderno' sem ter conseguido ser plenamente 'moderno', chegou à modernidade tardia sem ter rompido com a condição periférica. Ganhou uma agenda imensa, desafiadora, enigmática.

Ainda assim, a sociedade não está parada no tempo ou desinteressada de seu futuro. A seu modo, está indo à luta: questionando escolhas eleitorais, forçando a interposição de uma pauta "social" à agenda política nacional, agitando-se e protestando nas zonas rurais e nas periferias urbanas, onde exibe seu descontentamento. Não se mostra facilmente componível e tem cobrado um alto preço de todos aqueles que se dispõem a tentar algum movimento virtuoso de integração e de composição social. Embora mais bem encaixado na vida social, o problema da reconciliação (da articulação virtuosa) entre o individual e o comunitário, entre o público e o privado, continua em aberto.

\section{Modernidade tardia e condição periférica}

Para vencer as eleições presidenciais de 2002, Luís Inácio Lula da Silva recebeu um voto de confiança tanto de amplas camadas populares quanto de 
boa parte das elites, algumas das quais, como as empresariais e as financeiras, apostavam em sua capacidade de promover o desenvolvimento, ainda que receassem a imposição de mudanças estruturais na economia. Afinal, no programa com que disputou e venceu as eleições presidenciais, o PT havia proposto a consecução de três grandes diretrizes estratégicas: aprofundar a democracia, combater a exclusão social e reduzir a vulnerabilidade externa do país. Imaginava-se que um governo impulsionado pelos compromissos históricos do PT e pela agenda desenvolvimentista sustentada por amplas faixas do movimento democrático acabasse por aperfeiçoar e aumentar o controle sobre os fluxos de capitais e a taxa de câmbio.

A disposição petista de chegar à Presidência exigiu um movimento de cautela e prudência, refletido no discurso mais ameno que prevaleceu na fase final da campanha, quando da divulgação da Carta aos brasileiros, documento em que se fazia firme declaração de respeito a todos os compromissos econômicos e financeiros assumidos pelo Estado brasileiro e reduzia-se bastante a ênfase que o PT costumava conceder à questão social.

Haveria, no entanto, mais 'pragmatismo' que 'realismo'. Ao tomar posse em janeiro de 2003, Lula anunciou à sociedade um ministério eclético e moderado, que reunia - sem critérios claramente explicitados - quadros partidários, empresários e parlamentares de partidos aliados. Designou um banqueiro para o Banco Central e fixou, como eixo de gravitação do governo, uma equipe econômica ortodoxa, a qual foi encarregada de dar continuidade à política de ajuste fiscal e estabilização monetária em vigor.

Além de contido pela aceitação dos termos do jogo econômico, o governo continuou pensando o Estado como um aparelho a ser ajustado e 'contabilizado', sem se preocupar com a questão da qualidade dos serviços públicos e sem dar qualquer passo em direção a uma reforma ético-política do Estado. Ou seja, manteve o imaginário social preso a uma visão negativa do Estado e pouco contribuiu para dar maior agilidade à máquina pública e democratizá-la estabelecendo novos mecanismos de participação popular e de controle social.

Para piorar, reiterou a prática tradicional de preencher de forma unilateral os cargos públicos mais estratégicos (assessorias superiores, direção de empresas e autarquias, além, evidentemente, da estrutura administrativa dos ministérios), que foram entregues ou à burocracia partidária ou a profissionais do sindicalismo. Em boa medida, o PT 'ocupou' o Estado. Governo e partido se interpenetraram de forma deletéria, misturando seus negócios, sua dinâmica e seus interesses. Finalmente, para se sustentar em termos parlamentares, o governo Lula abriu sua coalizão ainda mais à direita, incorporando e patrocinando partidos que lhe impuseram um alto preço político e administrativo e ajudaram a que se criassem, dentro do governo, espaços de 'compra-e-venda' de apoios, de cargos e de verbas. Nada disso foi, obviamente, sem conseqüências. 
Ao se iniciar o ano de 2005, ao mesmo tempo em que passava a sofrer a pressão de suas próprias bases, desejosas de um maior ímpeto reformador, o governo começou a dar mostras de que iria se dedicar antes de tudo à busca de um segundo mandato para Lula. Para falar usando termos que se generalizaram na crônica política brasileira, passou a se dedicar intensivamente a um 'projeto de poder', desinteressando-se da elaboração e da implementação de um 'projeto de sociedade'.

Ao se combinar com a baixa performance administrativa do governo e com sua falta de clareza programática, a opção pela recondução de Lula expôs o governo aos diferentes apetites políticos, partidários e corporativos do país. Antes do final do semestre, o governo estava acossado pela revelação de que se armara, por dentro dele e sob patrocínio dele, uma ampla e complicada rede de corrupção destinada a repassar recursos financeiros não-declarados a partidos e a políticos tendo em vista a obtenção de apoio político no Congresso e a organização de fundos eleitorais. A cúpula dirigente do PT, alguns de seus deputados e diversos operadores governamentais surgiram no centro dessas operações, como maestros de uma orquestra corporativa e fisiológica que, de modo inusitado e inesperado, voltou a fazer sangrar a cultura republicana do país.

Repuseram-se, assim, uma tradição e uma prática usual na política nacional, mas com alguns agravantes: 1) a operação foi turbinada pelas novas condições estruturais da sociedade, por sua fragmentação, pela maior fragilidade do Estado e pelo declínio da capacidade de direção política dos partidos; 2) foi também impulsionada por uma inédita 'monetarização' dos relacionamentos políticos e por uma igualmente inédita 'colonização' econômica da política. A aceitação dos termos do jogo econômico, expressa na política econômica ortodoxa e na determinação de se fazer o máximo para 'blindar' a economia - isto é, deixá-la fora do alcance da regulação estatal e das negociações em torno das políticas sociais -, desdobrou-se assim na entrega de todo o Estado político (instituições, procedimentos e escolhas) ao 'mercado político'.

As circunstâncias político-econômicas e sócio-culturais correspondentes à fase globalizada do capitalismo e à modernidade radicalizada (Beck, 2003; Bauman, 2000) estão impondo um alto preço à vida política nacional. Tanto quanto o mundo, a sociedade brasileira também está hoje atravessada por dinâmicas de diversificação, fragmentação e multiplicidade de interesses. A desorganização do mundo do trabalho, ao lado da intensa mobilidade dos capitais, da financeirização e da transnacionalização das economias, fazem que a sociedade deixe de poder continuar se reproduzindo mediante regras e centros claramente reconhecidos. Os Estados e os governos ficam cercados pela economia internacionalizada, que não podem controlar, e pelas demandas e pressões internas a seus territórios, que não podem refrear nem atender. Os governos governam pouco, às vezes nem governam. Em 
maior ou menor grau, as diferentes mediações políticas e sociais estão ficando comprometidas, e minam as bases da autoridade política.

Tudo isso cria uma ainda maior confusão entre o interesse público e o privado. Desse ponto de vista, a democratização contemporânea - da política, dos relacionamentos, do poder - ressente-se com um súbito declínio do espírito republicano, coisa que, no caso brasileiro, significa a exacerbação de uma característica já infiltrada na corrente sanguínea da experiência social.

Além do mais, as concretas condições brasileiras não são apenas as da modernidade tardia, mas são também as da periferia do sistema capitalista. Isso faz com que o país conviva com uma verdadeira tragédia social, imposta pelo prolongamento do passado e aumentada pelos próprios termos da modernidade tardia. O Brasil atual caminha entre miséria 'colonial' e miséria 'neoliberal', entre o subemprego tradicional e o desemprego estrutural. Ainda não resolveu a questão da terra, mas apresenta altos índices de agricultura capitalizada e de agrobusiness.

No contexto da modernidade tardia e periférica, é ainda mais difícil desnudar os expedientes que o poder econômico usa para submeter a política. Os brasileiros, em particular, sabem que alguns poderosos esquemas de corrupção e de malversação de fundos públicos existem e operam, mas não conseguem saber onde eles estão e como fazem para agir e se reproduzir. Esforços de investigação - como os que têm sido desenvolvidos pelas diferentes Comissões Parlamentares de Inquérito que funcionam no Congresso Nacional desde julho de 2005 - são neutralizados por minúcias jurídicas e manobras protelatórias e não chegam a ter maiores conseqüências práticas, como que a revelar a fraqueza das instituições e a baixa eficácia dos sistemas.

Parte da atual crise brasileira deriva do fato de que o Estado e a política ingressaram em um estágio de 'sofrimento': estão afetados, de certo modo paralisados, pelo cruzamento de modernidade tardia e de condição periférica (Nogueira, 2004). Nada funciona muito bem em suas práticas e organizações, nada satisfaz, nada parece ter força suficiente para alterar o rumo das coisas. Como reação, sobem as taxas de angústia e de ansiedade, aumenta a inquietação e disseminam-se atitudes de revolta, ceticismo e niilismo, muitas vezes retóricas e impotentes para produzir consensos, contra-tendências consistentes ou mudanças efetivas. $\mathrm{O}$ 'social' se agita muito, mas não consegue pressionar de fato os governos nem interferir no direcionamento da ação estatal.

É como se estivéssemos a assistir ao esgarçamento da nossa eticidade, à diluição das condições necessárias para uma boa vida republicana. As potências da particularidade parecem estar mais livres do que nunca, e tendem a arrastar consigo os movimentos destinados a compor o individual (ou o interesse privado) com aquilo que é comum, com o interesse público. Estamos carecendo de dinâmicas intersubjetivas fortes, de doses mais expressivas de 'ação comunicati- 
va' (Habermas) e de contenção dos excessos reiterados pela própria experiência social. Falta-nos, digamos assim, um Estado ético que funcione como referência e que, impulsionado por uma sociedade civil politizada, pelos cidadãos mobilizados, controle o Estado político (os governantes, o sistema, a classe política) e garanta a prevalência democrática do público sobre o privado.

\section{Notas}

1 Professor livre-docente de Teoria Política da Universidade Estadual Paulista (Unesp). Doutor em Ciência Política pela Universidade de São Paulo (USP). <nogueira@fclar.unesp.br>

\section{Referências}

BAUMAN, Zigmunt. 2000. Em busca da politica. Rio de Janeiro: Zahar.

BECK, Ulrich. 2003. Liberdade ou capitalismo: Ulrich Beck conversa com Johannes Willms. São Paulo: Editora Unesp.

BUARQUE DE HOLLANDA, Sérgio. 1963. Raízes do Brasil. $4^{\mathrm{a}}$ ed. Brasília: Editora Universidade de Brasília.

CAMPELLO DE SOUZA, Maria do Carmo. 1976. Estado e partidos políticos no Brasil (1930-1964). São Paulo: Alfa-Omega.

LEAL, Victor N. 1975. Coronelismo, enxada e voto: o município e o regime representativo no Brasil. $2^{\text {a }}$ ed. São Paulo: Alfa-Omega.
NABUCO, Joaquim. 1988. O Abolicionismo. Petrópolis: Vozes.

NOGUEIRA, Marco A. 1998. As possibilidades da política: idéias para uma reforma democrática do Estado. São Paulo: Paz e Terra. .2004. Um Estado para a sociedade civil: temas éticos e políticos da gestão democrática. São Paulo: Cortez.

SANTOS, Wanderley Guilherme dos. 1979. Cidadania e justiça: a política social na ordem brasileira. Rio de Janeiro: Campus.

VIANA, Oliveira. 1987. Instituições politicas brasileiras. Belo Horizonte: Itatiaia; São Paulo: Edusp. 
